Miloš D. Đurić

$81^{\prime} 255.2: 62$

Univerzitet u Beogradu

https://doi.org/10.18485/climb.2017.5.2.ch18

Elektrotehnički fakultet

\title{
STRUKTURA I ZNAČENJE SLOŽENICA U DISKURSU ELEKTROTEHNIKE
}

\section{Sažetak}

U ovom radu se analiziraju neki aspekti strukture i značenja složenica u diskursu elektrotehnike na materijalu engleskog i francuskog jezika. Najpre se razmatraju neki prethodni, a zatim tekući pristupi složenicama. Klasifikacije složenica, kao i semantičke relacije njihovih konstituenata, koje su preuzete iz literature, primenjene su na primere iz korpusa elektrotehničkog registra. Uzeti su u obzir i istraživački rezultati iz računarske lingvistike, koji se mogu primeniti na složenice iz ove vrste diskursa.

Ključne reči: složenice, semantičke relacije, sintaksa, engleski jezik, francuski jezik, podaci zasnovani na korpusu, diskurs elektrotehnike.

Prema literaturi, u engleskom jeziku tehničkih nauka, najčešća kategorija novih leksičkih jedinica, pored izvedenica, jesu složenice (FišerPopović 1981: 160). Diskurs elektrotehnike, kao podskup skupa tehničkog diskursa, u tom smislu, nije izuzetak. Naime, ova vrsta diskursa obiluje složenicama, naročito kada su u pitanju neologizmi. Argument za ovaj odabir nalazim i u literaturi, prema kojoj, interpretacija složenica zadaje dosta poteškoća kako studentima tehnike, tako i inženjerima (Bartolić 1979: 47). U literaturi se navodi i da naročito u tehničkom diskursu složenice nose veliki deo informacija (Barker and Szpakowicz 1998: 96). Fišer-Popović konstatuje da su najfrekventnije složenice imeničkog tipa. Međutim, u mom korpusu postoje brojni primeri složenica sa strukturom pridev+imenica. Potkrepljenje da uključimo složenice sa ovom strukturom našli smo u okviru generativne semantike (Levi 1978). Ovu struk- 
turu složenica obrađuje i Cvetana Krstev, mada navodi statistiku za srpski jezik kada kaže da je postoji mnogo složenica u srpskom sa strukturom $<$ A $><$ N $>$ (Krstev 2008: 117).

Ako se oslonimo na tvrdnje iznete u literaturi, naročito u vezi sa interpretacijom, pa samim tim i prevođenjem složenice na srpski jezik, onda bi se moglo konstatovati da su relevanti elementi: struktura složenice i značenje složenice. Složenice se pojavljuju na uzorku koji sam ispitivao, a pogodne su zato što skraćuju informaciju, koja treba da se prenese, istovremeno zadržavajući preciznost sadržaja na koji se odnose. Prilikom utvrđivanja izvesnih pravila za generisanje potencijalno novih složenica, potrebno je razmotriti kako strukturu njihove forme, tako i sadržaja, kako se navodi u literaturi (Fišer-Popović 1981: 160).

$U$ literaturi se navodi da iznalaženje odgovarajuće definicije složenica, koja bi bila važeća za veći broj jezika, nije trivijalan zadatak (Ziering and van der Plas 2014: 1047). Isto tako, prema literaturi, automatska interpretacija složenica je dugotrajan problem u oblasti obrade prirodnog jezika (Lapata 2002: 357).

U literaturi se mogu naći različita određenja složenice, kao i različite klasifikacije. U ovom radu ću koristiti kao radnu definiciju, određenje Ane Fišer-Popović. Ova autorka ističe postojanje neusaglašenosti u pogledu definisanja složenica, naročito obraćajući pažnju na kriterijume za razgraničenje složenica od sintaksičkih grupa reči. Ova lingvistkinja definiše složenice kao gramatički i semantički osamostaljene leksičke oblike sa jedinstvenim značenjem i gramatičkom funkcijom (Fišer-Popović 1981: 160). Potom, ona daje preglednu listu najrelevantnijih osobina složenica ${ }^{1}$, koje možemo da primenimo i na složenice iz diskursa elektrotehnike i računarstva. Ove osobine bi bile sledeće. Složenice se dobijaju kompozicijom, odnosno, „srastanjem dve ili više slobodnih morfema i pritom grade po sintaksičkoj funkciji“ jedinstvenu jedinicu. Na dalje, složenice se razlikuju od imeničkih sintagmi i na fonološkom nivou, i to po specifičnom akcenatskom obrascu. Pomenuta autorka napominje da u jeziku tehničkih nauka postoji mali broj složenica egzocentrične strukture, a da je struktura složenica uglavnom endocentrična i to sa fiksnim redosledom elemenata. Ukoliko je u pitanju imenička složenica, onda poslednji element (koji je imenica) jeste centar leksičkog i gramatičkog značenja, a modifikuju

1 Napominjem da ona pre svega govoori o imeničkim složenicama. 
je elementi koji joj prethode (Fišer-Popović 1981: 161). Takođe, ističe da značenje složenica nije prost zbir značenja elemenata, već postoji dodatna semantička komponenta koja je karakteristična za složenicu kao celinu. Ne manje bitna karakteristika jeste stabilnost složenica u upotrebi, što je, prema citiranoj autorki, izraženo njihovim ortografskim i fonološkim oblikom.

Pored definicije Fišer-Popović, uzimam kao polaznu tačku i prilično široko određenje koje nalazim kod Cvetane Krstev u okviru rezultata iz domena računarske lingistike. Osvetljavajući različite aspekte složenica ova autorka primenjuje integrisan pristup automatskom prepoznavanju i generisanju složenica (Krstev 2008: 106-136), koji uspešno primenjuje na srpski, francuski i engleski jezik.

Pošto moj korpus pripada registru nauke (preciznije elektrotehnike i računarstva), onda sam se rukovodio i rezultatima do kojih je došla i Jelena Vujić, analizirajući impozantan korpus od 1220 bipolarnih imeničkih složenica, i to strukturalnom metodom (Vujić 2004: 157). Jelena JelićVujić je temeljno analizirala složenice kao termine kompjuterskog registra (Jelić-Vujić 2007: 175-180) pružajući relevantne statističke podatke koji su imali reperkusije i na moja istraživanja.

Još jedan od problema, koji se ističe u literaturi, jeste problem prilikom prevođenja. Naime, postoji zajednički strukturni domen, a sužavanje ili modifikovanje informacije osnovnog širokog pojma realizuje se u prevodu dodavanjem postpozicionalnih struktura (Bartolić 1979: 47). Ista autorka ističe još jedan problem koji se javlja u diskursu tehničkih nauka. Naime, javljaju se više mogućnosti sintaksičkog parafraziranja, naročito višečlanih složenica, što se ilustruje sledećim primerom iz njenog korpusa. Npr. složenica beam intensity modulation terminal, može se sintaksički parafrazirati kao: 1 . A terminal for the modulation of the intensity of a beam (priključak za modulaciju intenziteta elektronskog snopa), 2. A terminal for modulating the intensity of a beam (priključak za moduliranje intenziteta elektronskog snopa) i 3. A terminal which/that modulates the intensity of a beam (priključak koji modulira intenzitet elektronskog snopa) (Bartolić 1979: 47).

Pošto je, prema literaturi, jedan od relevantnih kriterijuma za precizno definisanje složenice analiza na planu sadržaja (Fišer-Popović 1981: 161), onda ću razmotriti, prema modelu ove autorke, neke semantičke os- 
obine složenica u diskursu elektrotehnike i računarstva. Najpre ću analizirati par primera iz mogu korpusa koji su reprezentativni za binarne ili kanoničke složenice sa strukturom $(\mathrm{N})_{n}+\mathrm{N}$. One su uglavnom imeničke (stoga i figurira $N)$, a (N) je uređen konačan skup on $n$ elemenata pri čemu je $n \geq 1$.

Ono što se ističe u relevantnoj literaturi jeste semantička analiza prema kojoj se iznalazi da u složenicama, pored pojedinačnih značenja konsitutenata složenice, postoji prisutna i dodatna semantička komponenta, koja obično sužava opšte značenje složenice, a istovremeno utvrđuje precizne granice pojma određenog tim konstituentima (Fišer-Popović 1981: 162). Pogledaćemo par primera iz mog korpusa. Na primer, složenica electric polarization se prema ovom modelu interpretira na sledeći način:

electric polarization $=($ dielectric $)-$ electric + polarization, polarization of electricity that occurs in a dielectric.

$\mathrm{Na}$ dalje, složenica magnetic flux se analizira sa semantičkom komponentom quantity: magnetic flux = (quantity) - magnetic + flux, measure of magnetism quantity; ili složenica direct current koja se interpretira sa sledećom semantičkom komponentom: direct current = (direction) direct + current, electric current that flows in the same direction.

$U$ literaturi se ističe i da je leksičko značenje složenica tesno povezano sa njihovom strukturom, pa samim tim, i značenjem koje proističe iz rasporeda konstituenata složenice. Konstatuje se da je redosled konstituenata strogo utvrđen, pa sledstveno tome, svaka promena redosleda konstituenata povlači za sobom i promenu leksičkog značenja složenice (Fišer-Popović 1981: 164).

Kao i citirana autorka, i lingvistkinja Anna Maria di Sciullo (2005: 15) ističe da se konstituenti složenice ne mogu preurediti, a da taj rezultat preuređivanja ne bude ili besmisleni sled ili pak složenica koja ima drugačiju interpretaciju u odnosu na nameravanu složenicu sa fiksnim redosledom konstituenata. Ova autorka operiše pojmom asimetrije i konstatuje da je asimetrija karakteristično svojstvo složenica i dodaje da je asimetrična konstituentska nadređenost deo složenica pošto se vezivanje i upravljanje posmatraju u okviru reči (di Sciullo 2005: 15). Kako bih ilustrovao ove prethodno izrečene tvrdnje, navešću u tabeli primere složenica di Sciullove i odmah paralelno dajem svoje primere iz engleskog i francuskog diskursa elektrotehnike².

Asterisk * konvencionalno označava rđavo oblikovane primere, dok $\neq$ označava složenicu koja je dobro oblikovana ali čije rezultujuće značenje nije odgovarajuća interpretacija polazne složenice. 
Култура и/или наука

\begin{tabular}{|l|l|l|}
\hline $\begin{array}{l}\text { Primer Di Sciullove } \\
\text { (2005: 15) }\end{array}$ & $\begin{array}{l}\text { Primer iz engleskog diskursa } \\
\text { elektrotehnike }\end{array}$ & $\begin{array}{l}\text { Primer iz francuskog } \\
\text { diskursa elektrotehnike }\end{array}$ \\
\hline paper bag- *bag paper & $\begin{array}{l}\text { impulse inertia- } \\
\text { *inertia impulse }\end{array}$ & $\begin{array}{l}\text { transistor tétrode - } \\
\text { *tétrode transistor }\end{array}$ \\
\hline hard disk - *disk hard & $\begin{array}{l}\text { radar equation - } \\
\text { *equation radar }\end{array}$ & $\begin{array}{l}\text { microphone condensateur - } \\
\text { *condensateur microphone }\end{array}$ \\
\hline rail road $\neq$ road rail & load line $\neq$ line load & effet tunnel $\neq$ tunnel effet \\
\hline hit and run $\neq$ run and hit & light valve $\neq$ valve light & ceil magique $\neq$ magique œeil \\
\hline
\end{tabular}

Tabela 1. Primeri sintaksičkog preuređivanja konstituenata složenice i rezultujući sintaksički ajtemi iz Di Sciullo (2005)

i iz mog korpusa engleskog i francuskog diskursa elektrotehnike.

Kao što se vidi iz tabele, postoje slučajevi složenica čijim se sintaksičkim preuređivanjem dobijaju rđavo oformljeni ajtemi (*bag paper, *disk hard, *inertia impulse, * equation radar, *tétrode transistor, *condensateur microphone), a vidimo i primere složenica čijim se sintaksičkim preuređivanjem dobijaju dobro oformljene složenice (road rail, run and hit, line load, valve light, tunnel effet, magique œil), s tim što imaju drugačije značenje od polaznih složenica (rail road, hit and run, load line, light valve, effet tunnel, magique œil).

Pored Di Sciullo, autorka koja ističe relevantnost redosleda konstituenata u složenice je Cvetana Krstev. Ova autorka posvećuje jedan odeljak u okviru svoje sveobuhvatne studije redosledu konstituenata kod složenica (Krstev 2008: 116-117). Mada, navodeći srpske primere, ova autorka dopušta u izvesnim primerima odstupanja (npr. muva ce-ce $=c e-c e$ muva; ekonomsko-finansijski = finansijsko-ekonomski) (Krstev 2008: 116).

Autori ističu da je u razmatranju semantičkih odnosa najveći doprinos dala transformaciona gramatika (Fišer-Popović 1981: 164). Preciznije, prema izvesnim autorima, nove složenice generišu se različitim kombinacijama prostih i izvedenih leksičkih oblika, dok unutrašnja struktura ovih složenica odražava sintaksičke odnose karakteristične za cele rečenice (Fišer-Popović 1981: 164).

$\mathrm{U}$ literaturi se pominje i poluautomatsko prepoznavanje odnosa između konstituenata, odnosno modifikatora (najčešće) imenice. Ovi odnosi se nazivaju odnosi modifikatora imenice (Barker and Szpakowicz 1998: 96). Pomenuti model, koji dolazi na osnovu istraživačkih rezultata iz računarske lingvistike, primenjujem na binarne, tj. kanoničke složenice, 
na taj način proširujući semantičku klasifikaciju Ane Fišer-Popović. Pogledaćemo kako se klasifikacija ovih autora može fino primeniti na diskurs elektrotehnike i računarstva. Parafraze su korisne, a prema ovim autorima, služe za definisanje složenica, kao i da pomognu prilikom interpretacije (Baker and Szpakowicz 1998: 97). Pa tako, pararaza engleske složenice ion migration potpuno odgovara parafrazi francuske složenice migration ionique, a isto tako relacije engleske složenice primary current odgovaraju relacijama francuskog ekvivalenta courant primaire, kao i primary voltage i tension primaire. Međutim, potencijalni problemi nastaju kod višečlanih složenica i kod složenica čije parafraze nisu ekvivalentne. Pa tako imamo englesku višečlanu složenicu private wire service kojoj odgovara francuski ekvivalent exploitation sur les circuits pour service privé, a gde se parafraze ipak razlikuju. Slično tome, postoje slučajevi gde za jednu englesku binarnu složenicu (npr. decay time) pronalazimo dva francuska ekvivalenta u korpusu (durée de decharge, ali i durée de retour au zéro).

Ovaj potonji primer iz francuskog jezika (durée de retour au zéro) je zanimljiv zato što pokazuje da se u literaturi ovakvi sledovi tretiraju kao složenice. Slično tome, i kada se razmatraju složenice u srpskom jeziku, dozvoljavaju se sintaksičke varijante, pa se kaže da neke složenice mogu da ispoljavaju nekoliko različitih sintaksičkih oblika (Krstev 2008: 119). Ova autorka navodi primer složenice ministar za unutrašnje poslove, čija je struktura imenica+predlog+pridev+imenica, i kaže da ova složenica može imati alternativni oblik ministar unutrašnjih poslova, čija je struktura imenica+pridev+imenica, a poslednja dva konstituenta su u genitivu (Krstev 2008: 120).

lako se klasifikacija semantčkih relacija koju predlažu citirani autori (Barker and Szpakowicz 1998: 97-98) može fino primeniti na veliki broj primera iz mog korpusa, ove relacije ipak ne mogu da se savršeno uklope u primere višečlanih složenica ili pak složenica koje imaju više od jedne moguće interpretacije. U zaključku svog rada, oni konstatuju da bi trebalo da se iznađe teorijski čvršći pristup kojem bi sledilo dalje eksperimentisanje sa primerima (Barker and Szpakowicz 1998: 102).

U pogledu analize strukture složenica, u literaturi se pominje da se složenice mogu analizirati na više nivoa i na osnovu više kriterijuma (Vujić 2004: 157). Ova autorka deli složenice i to na četri nivoa. Lingvistkinja Jelena Vujić najpre uvodi kriterijum klase reči kojoj pripadaju neposredne 
konstituente, a to je prvi nivo analize. Ona je utvrdila 18 podtipova u koje se odlično uklapaju naši primeri engleskih složenica iz korpusa, a to su³: 1 . $\mathrm{N}+\mathrm{N}$ (access time), 2. $\mathrm{N}+\mathrm{V}$ (cascade carry), 3. $\mathrm{V}+\mathrm{N}$ (connect time), 4. V+V (write protect), 5. Adj+N (acoustic coupler), 6. N+Adj (device dependent), 7. Adj+V (cold boot), 8. V+Adv (stand alone), 9. Adv+N (down time), 10. Prep $+\mathrm{N}$ (off line), 11. N+Prep (comment out), 12. Prep+V (nemamo primer), 13. V+Prep (log on), 14. Adj+Prep (built in), 15. Num+N (zero flag), 16. Conj+N (AND operation), 17. Pron+N (its loop), 18. Part+N (nemamo primer). Dakle, vidimo da se klasifikacija koju predlaže lingvistkinja Jelena Vujić fino uklapa u primere iz diskursa elektrotehnike, mada za neke njene relacije nemamo primere ili su nam neki primeri „nategnuti“, međutim, globalno posmatrano, njena klasifikacija je odlična za ovaj registar.

Na dalje, ova autorka, na drugom nivou klasifikacije klasifikuje podtipove na osnovu kriterijuma odnosa između determinanta i determinantuma (Vujić 2004: 157), koju ona obeležava kao modifier M i head H. Ona je u svom korpusu utvrdila tri tipa složenica: $1 . \mathrm{M}+\mathrm{H}, 2$. $\mathrm{H}+\mathrm{M}$ i 3. $\mathrm{H}+\mathrm{H}$. Primeri za ove tipove bili bi: user interface, output i programmer analyst.

Vujićeva uvodi i treći kriterijum analize, gde se klasifikacija vrši na osnovu morfološke strukture neposrednih konstituenata, a četvrti nivo klasifikacije konstituenata podrazumeva kriterijum klase (za imenice i prideve), kriterijum tranzitivnosti (za glagole). Na petom nivou, ova autorka klasifikuje složenice prema kategoriji broja (Vujić 2004: 158).

Pošto u mom korpusu ima dosta složenica čija struktura prevazilazi dva konstituenta, odnosno, nalazimo složenice koje se sastoje od tri, četiri i više konstituenata, pogledaćemo i mogućnost primene analize Ljerke Bartolić (1979: 48-49) na primere iz mog korpusa. Postoje primeri jednog modifikatora za kojim sledi upravna reč/centar (npr. water power, truth table), 2 modifikatora + centar (npr. cathode ray tube, command file processor), 3 modifikatora + centar (npr. data base management system), 4 modifikatora + centar (npr. grandfather-father-son file system), 5 modifikatora + centar (npr. glow discharge electron beam gun software). Ovakve složenice pronalazimo u diskursu elektrotehnike, a razloge za to, citirana autorka vidi u tome što su ovakve i slične složenice kraće nego ekvivalentne deskriptivne fraze, a na taj način se tehnička informacija može pre-

3 Navodimo broj podtipa, njegovu strukturu, a u zagradi primer iz našeg korpusa. Svi podtipovi su prema Vujić (2004: 157). 
neti „,..] u kondenziranijem obliku a da se pri tome zadržava pojmovna jasnoća izražaja" (Bartolić 1979: 49).

Citirana autorka uvodi klasifikaciju prema specifičnim kriterijumima (Bartolić 1979: 50-54), koji se mogu interpretirati kao semantičke relacije koje nalazimo kod drugih autora (npr. kod Levijeve). To su: 1. RAD, i to princip rada (npr. gravity conveyer), medijum u radu (npr. water turbine), sredstvo rada (npr. hand brake), karakteristični radni deo (npr. jet condenser), osoba koja je formulisala princip rada (npr. Hamming code), 2. MATERIJALI (npr. glass insulator), 3. SVRHA PRIMENE (npr. transmission line), 4. MESTO (npr. boilerplate), 5. PROFESIONALNO ANGAŽOVANE OSOBE ILI ORGANIZACIJE (npr. research engineer), 6. ОВLIK (npr. butterfly valve). Ovo su samo neke od relacija koje Bartolićeva navodi, a možemo da nađemo odgovarajuće primere u našem korpusu koji odgovaraju njenim relacijama.

Pored sintaksičkih i semantičkih kriterijuma, zanimljivi su i ortografski kriterijumi, koji se pominju u relevantnoj literaturi (Jelić-Vujić 2007: 180). Lingvistkinja Jelić-Vujić posvećuje odeljak i ortografskom kriterijumu za složenice u kompjuterskom registru.

U tentativnim zaključnim napomenama, primetili bismo da složenice u diskursu elektrotehnike mogu imati različite sintaksičke i semantičke interpretacije. $U$ engleskom jeziku je poslednja komponenta u nizu upravna reč, odnosno centar složenice (npr. edge lighting, earthed grid, ed$d y$-current brake), dok je u francuskom jeziku na prvom mestu upravna reč, pa tek onda slede modifikatori (npr. éclairage par la tranche, grille suppresseuse, frein magnétique). Neki preliminarni zaključci bi bili da se raznovrsnost sintaksičkih i semantičkih međuodnosa može analizirati iz ugla poruke koju treba kondenzovati i preneti recipijentu informacije. Prilikom analize semantičkih relacija, koje se predlažu u citiranoj literaturi, uočene su izvesne semantičke pravilnosti koje bi potencijalno mogle da se koriste za formulisanje pravila ili algoritma prema kome se generišu nove složenice u engleskom i francuskom jeziku. lako nismo primenili dosledno ove relacije na srpski jezik, smatramo da bi neke od uočenih pravilnosti mogle da važe i za složenice u srpskom jeziku.

$U$ vezi sa sintaksičkim karakteristikama smo uočili da se redosled konstituenata u okviru složenice ne može menjati, a da se ne izgubi smisao složenice. Istovremeno, sintaksičko skraćivanje poruke, koju složenica treba da prenese, vrši se na taj način da se ne izgubi jasnoća, ali ni pre- 
ciznost karakteristična za diskurs elektrotehnike. Ukoliko se u obzir uzmu različite klasifikacije i različiti parametri za definiciono određenje složenica kao i relacija unutar njih, može se videti da su složenice dinamične strukture koje imaju fiksni raspored elemenata i semantičke međuodnose koji se primenjuju kako na kanoničke, tj. binarne složenice, tako i na višečlane složenice u ovoj vrsti diskursa. Ovo su samo preliminarni rezultati analize, a mogu se proširiti daljim, finijim elaboracijama.

\section{Literatura}

Barker, Ken and Stan Szpakowicz. "Semi-automatic recognition of noun modifier relationships." COLING 98 Proceedings, eds. Martin Kay \& Eva Hajičová, 96-102. Montréal: Université de Montréal and Association for Computational Linguistics, 1998. Print.

Bartolić, Ljerka. „Imenske složenice u tehničkom engleskom jeziku.“ Strani jezici 1-2 (1979): 47-58. Print.

Di Sciullo, Anna Maria. "Decomposing compounds." SKASE Journal of Theoretical Linguistics 2 (2005): 14-33. Print.

Fišer-Popović, Ana. „O nekim semantičkim osobinama imeničkih složenica u engleskom jeziku tehničkih nauka." Strani jezik struke u teoriji i praksi, ed. Nadežda Vinaver, 160-167, Beograd: Udruženje univerzitetskih nastavnika i drugih naučnih radnika Srbije, 1981. Print.

Jelić-Vujić, Jelena. „Složenice kao termini kompjuterskog registra." Language for Specific Purposes, eds. Igor Lakić \& Nataša Kostić, 175-180. Podgorica: Institut za strane jezike Univerzitet Crne Gore, 2007. Print.

Krstev, Cvetana. Processing of Serbian: Automata, Texts and Electronic Dictionaries. Belgrade: Faculty of Philology, 2008. Print.

Levi, Judith N. The Syntax and Semantics of Complex Nominals. New York: Academis Press, 1978. Print.

Vujić, Jelena. „Morfološka analiza bipolarnih imeničkih složenica u kompjuterskom registru." Lingvističke analize: Zbornik u čast 25 godina Instituta za strane jezike u Podgorici, eds. Slavica Perović \& Vesna Bulatović, 155-166. Podgorica: Institut za strane jezike, 2004. Print.

Ziering, Patrick and Lonneke van der Plas. "What good are 'Nominalkomposita' for 'noun compounds': Multilingual extraction and structure analysis of nominal compositions using linguistic restrictors." Proceedings of COLING 2014, eds. Junichi Tsujii \& Jan Hajic, 1047-1058. Dublin: Dublin City University and Association for Computational Linguistics, 2014. Print. 
Miloš D. Đurić

Faculty of Electrical Engineering

University of Belgrade

\section{THE STRUCTURE AND MEANING OF COMPOUNDS IN ELECTRICAL ENGINEERING DISCOURSE}

\section{Summary}

The aim of this paper is to describe and explain certain aspects of compounds in electrical engineering discourse. The author introduces the scope and previous accounts. Subsequently, certain unitary tenets pertinent to the subject are further explained and illustrated. Diverse classifications and semantic relations of compound constituents are presented and applied to the corpus-based data. The next part discusses the applicability of these classifications and relations to the phenomena under investigation. Finally, the last part lists the relevant findings about compounds in this specific discourse type.

Key Words: Compounds, Semantic Relations, Syntax, the English Language, the French Language, Corpus-Based Data, Electrical Engineering Discourse. 